\title{
Genetic and Physiological Characterisation of Oenococcus oeni Strains to Perform Malolactic Fermentation in Wines
}

\author{
V. Renouf ${ }^{1 *}$, M. Favier ${ }^{2}$ \\ (1) LAFFORT BP 1733072 Bordeaux cedex, France \\ (2) SARCO, research subsidiary of the LAFFORT group- BP 40, 33072 Bordeaux, France \\ Submitted for publication: November 2009 \\ Accepted for publication: January 2010 \\ Key words: Oenococcus oeni, malolactic fermentation, bacteria selection, genetic and physiological abilities
}

\begin{abstract}
Malolactic fermentation (MLF) is a process that is increasingly conducted by Oenococcus oeni industrial strains. Recently, studies of the diversity of $O$. oeni strains have developed some potential genetic tools to characterise the abilities of the strains. During this work, a mutation on a partial sequence of the rpoB gene and the presence of some genes previously established to be present in the most performing strains were tested on some strains that are already marketed and some potential new strains. These tests were compared with a physiological test never previously taken into account: the tolerance to octanoic and decanoic acid, important inhibitory compounds in wines. Our objectives were to compare the relevance of the genetic tests currently available, that of resistance to medium chain fatty acids and the results of winemaking. Ultimately, it is clear that, as far as current knowledge is concerned, genetic tests are not yet sufficient to completely characterise the strain potential, and physiological tests therefore are always needed. The resistance to medium chain fatty acids is an interesting point to be considered to explain the difficulty that some strains have to resist inoculation in wine. But other criteria should also be characterised better, such as the duration of the latent phase between inoculation and the beginning of MLF, and the rate of degradation of malic acid by the different strains.
\end{abstract}

\section{INTRODUCTION}

Malolactic fermentation (MLF) is an important stage in winemaking, resulting in deacidification, the evolution of aroma and microbial stabilization. But, despite its importance, MLF is not always an operation that is perfectly controlled. Among the lactic acid bacteria (LAB) species present on grapes and in the must, the main species responsible for MLF is Oenococcus oeni (O. oeni). It is the main surviving species after alcoholic fermentation (AF). There is tremendous diversity between the strains of the $O$. oeni species. The recent sequencing of its genome shows that $O$. oeni does not have the mutS/L genes involved in DNA repair, enabling it to evolve rapidly (Marcobal et al., 2008) and thus acquire its great genetic diversity. Studies have explored the diversity of $O$. oeni strains (De las Rivas et al., 2004; Bilhère et al., 2009; Bon et al., 2009). These genetic investigations are more discriminating than the phenotype screening used until now, which was painstaking, slow and, above all, unreliable. One of the applications of these studies is to facilitate the selection of efficient industrial starters that are increasingly being used by winemakers.

Tolerance of ethanol is generally the main target of the investigations undertaken to select $O$. oeni starters, but in most cases it is a matter of many parameters that have a cumulative effect: temperature, $\mathrm{SO}_{2}$ concentration, low $\mathrm{pH}$ and the accumulation of toxic compounds. Even though $O$. oeni is an acidophilic bacterium (i.e. capable of developing in relatively hostile acid media and buffering its internal $\mathrm{pH}$ (Drici-Cachon et al., 1996; Guzzo et al., 2002), this tolerance has its limits and
MLF is generally problematic below $\mathrm{pH}$ 3.3. Regarding inhibitory compounds in addition to ethanol and $\mathrm{SO}_{2}$, the medium-chain fatty acids octanoic and decanoic acid (Lonvaud-Funel et al., 1988) take advantage of their short aliphatic chains to insert between the phospholipids of the membrane, affecting its fluidity and deteriorating its function. The levels of octanoic and decanoic acid depend on the yeast strains acting during AF, the presence of the undesirable yeast species Brettanomyces bruxellensis (Romano et al., 2008) and also on pH. For any yeast strain, the lower the wine $\mathrm{pH}$, the more the yeast produces these fatty acids. The initial level of sugars is also important: the higher the potential ethanol, the more the yeast produces these compounds, especially towards the end of fermentation (after $0^{\circ}$ Brix). These points underline the cumulative impact of different inhibitory parameters and also illustrate the importance of the compatibility between yeast and bacteria during winemaking.

This study dealt with the selection of $O$. oeni strains to perform MLF in difficult wines. Five strains that are already used as commercial starters were compared, with the strains being isolated from difficult wines with, respectively, high ethanol (IOEBSARCO 433a), low pH (IOEB-SARCO 268), and a high level of $\mathrm{SO}_{2}$ (IOEB-SARCO 384), and a strain detected in must before fermentation and not performing the MLF (IOEB-SARCO 455).

Firstly, a singular mutation on the rpoB gene was studied, which permitted the division of the $O$. oeni strain collection into two groups: those strains with superior fermentative abilities, and those that are more tolerant of $\mathrm{SO}_{2}$, acting and persisting 
during ageing (Renouf et al., 2009). Control was exercised over the presence of certain genes amongst those established by Delaherche et al. (2007) which are significantly most prominent in the strains with strong oenological abilities (Renouf et al., 2008), whereas they are only anecdotal in the weak strains. These genes were identified after a subtractive comparison between an $O$. oeni strain with good winemaking potential (IOEB-SARCO 1491) and another strain with lower winemaking potential (IOEB 8413). The 11 genes were present in the first strain, but not in the second. Another gene, DpsA, evidenced by Athané et al. (2008) and encoding for a Dps protein (DNA-binding protein from starved cell), was also studied. This type of protein is involved in environmental stress, notably acid resistance (Choi et al., 2000). In addition, tolerance to octanoic and decanoic acid was evaluated. This aspect, never previously taken into account during the selection of commercial strains, reflects both the bacterial resistance to the toxicity encountered in the wine and part of the interactions that occur between yeasts and bacteria.

Finally, the strains were subjected to winemaking in two wines possessing constraining parameters. For the red wines, the most important parameter, without any doubt, was the ethanol concentration, at $15.5 \%$ vol. In the white wines the $\mathrm{pH}$ played a more important role, hence a wine with a $\mathrm{pH}$ equal to 3.0 was used.

\section{MATERIALS AND METHODS}

\section{Bacterial strains}

The first five strains shown in Table 1 are industrial starters. The following three strains were isolated from constraining wines. IOEB-SARCO 455 is an indigenous strain exhibiting poor oenological qualities. IOEB 1491 was used as a positive control in genetic testing. All the strains were stored at $-80^{\circ} \mathrm{C}$ and cultivated in MRS medium.

TABLE 1

List of strains.

\begin{tabular}{ll}
\hline Name of the strain & Origin \\
\hline Lactoenos SB3 $^{\circledR}$ & Commercial starter provided by LAFFORT oenology \\
Lactoenos 350 & Commercial starter provided by LAFFORT oenology \\
Lactoenos 450 & Commercial starter provided by LAFFORT oenology \\
Lactoenos B16 & Commercial starter provided by LAFFORT oenology \\
Malolactic starter A & Commercial starter \\
IOEB*-SARCO** 268 & White wine, Burgundy \\
IOEB-SARCO 384 & White wine, Savoy \\
IOEB-SARCO 433a & Red wine, Cahors \\
IOEB-SARCO 455 & Red wine, Rhone valley \\
IOEB 1491 & Red wine, France
\end{tabular}

$*$ IOEB $=$ bacteria of the Institute of Oenology of Bordeaux, France.

**IOEB SARCO $=$ common collection between the Institute of Oenology of Bordeaux and SARCO, the research subsidiary of the LAFFORT group.

\section{DNA extraction}

During each extraction, a negative control of the extraction was made on sterile water. Some colonies were taken from pure culture and diluted in $1.5 \mathrm{ml} \mathrm{TE}$ buffer to an optical density $\left(\mathrm{OD}_{600 \mathrm{~nm}}\right)$ of 0.6 . Microtubes were centrifuged for $5 \mathrm{~min}$ at $10000 \mathrm{~g}$. The supernatant was discarded. The pellet was suspended gently in 600 $\mu \mathrm{L}$ of EDTA (50 mM, pH 8) containing $10 \mathrm{mg} / \mathrm{mL}$ of lysosyme. After incubation at $37^{\circ} \mathrm{C}$ for $1 \mathrm{~h}$ and 2 min of centrifugation at $10000 \mathrm{~g}$, the new supernatant was again discarded. A total of 600 $\mu$ L of Nuclei Lysis Solution (Promega, Genomic DNA Purification Kit Promega, Charbonnières Les Bains, France) was added and the suspension incubated at $80^{\circ} \mathrm{C}$ for $5 \mathrm{~min}$ and then brought to room temperature. Thereafter, $3 \mu \mathrm{L}$ of RNAse solution (Promega) were added with mixing by inversion, followed by incubation at $37^{\circ} \mathrm{C}$ for $30 \mathrm{~min}$, after which the sample was brought to room temperature. The next step was the addition of $200 \mu \mathrm{L}$ of Protein Precipitation Solution (Promega), and the mixture was vortexed for $20 \mathrm{~s}$. Microtubes were put into ice for $5 \mathrm{~min}$ and then centrifuged for $3 \mathrm{~min}$ at $10000 \mathrm{~g}$. The supernatant was transferred to a microtube containing $600 \mu \mathrm{L}$ of isopropanol at room temperature, and the suspension mixed by slow inversion. The mixture was then centrifuged for $2 \mathrm{~min}$ at $10000 \mathrm{~g}$ and the supernatant was eliminated. A total of $600 \mu \mathrm{L}$ of $70 \%$ room temperature ethanol was added. The microtubes were inverted many times to wash the pellet before the final stage of centrifugation for $2 \mathrm{~min}$ at $10000 \mathrm{~g}$. The ethanol was removed through aspiration. The pellet was dried at ambient temperature for $10 \mathrm{~min}$ under vacuum. Then 20 to 50 $\mu \mathrm{L}$ of water were added. The DNA was rehydrated at $4^{\circ} \mathrm{C}$ for one night and the samples were held at $4^{\circ} \mathrm{C}$ or $-20^{\circ} \mathrm{C}$ until PCR.

\section{Mutation of the rpoB gene}

The two partial sequences of the rpoB studied by Renouf et al. (2009) differed by a single mutation, named H (GenBank accession number EF612504.1) and L (GenBank accession number EF612503.1). Two Taqman ${ }^{\circledR}$ probes corresponding to each sequence were developed: 5'-FAM-pRpoBL-3'TAMRA-3' (pRpoBL) and 5'-TexasRed-pRpoBH-3'-BHQ2 (pRpoH), to be used in Q-PCR reactions according to the protocol specified by Renouf et al. (2009). Q-PCRs were run on each DNA strain. At the end of the amplification cycles, an allelic discrimination with the software provided with the thermocycler (CF96, Bio-Rad) was conducted in order to identify the mutation for each strain. During each Q-PCR operation, a negative control of the amplification reaction was implemented.

\section{Test for the presence of certain genes}

The presence of twelve genes was tested for by PCR (Table 2). These genes are encoded for cadmium transporting P-type ATPase, Dps ferritin, polysaccharide biosynthesis export protein, maltose phosphorylase, transcriptional regulator, alcohol-sugar dehydrogenase, copper chaperone, thioridoxin, glyceroltransferase involved in cell wall synthesis (Delaherche et al., 2007) and DpsA protein (Athané et al., 2008). PCR was conducted on $25 \mu \mathrm{L}$ of a mixture containing $2 \mathrm{ng}$ of DNA templates, $2 \mu \mathrm{L}$ of custom-made PCR Master Mix (MPBiomedicals) and 5 pmol of each primer. The reaction mixture was preheated for $5 \mathrm{~min}$ at $95^{\circ} \mathrm{C}$ and subjected to 30 cycles in an iCycler iQTM (Bio-Rad), each consisting of denaturing $\left(30 \mathrm{~s}, 95^{\circ} \mathrm{C}\right)$, annealing $\left(30 \mathrm{~s}, 55^{\circ} \mathrm{C}\right)$ and extension $\left(30 \mathrm{~s}, 72^{\circ} \mathrm{C}\right)$ steps. A negative control of the DNA extraction was also implemented. From all the DNA, each gene was tested by 
TABLE 2

List of the genes and the sequences of primers used.

\begin{tabular}{|c|c|c|}
\hline Gene targeted & Forward primer $\left(5^{\prime} \rightarrow 3^{\prime}\right)$ & Reverse primer $\left(5^{\prime} \rightarrow 3^{\prime}\right)$ \\
\hline Cadmium-transporting P-type ATPase - I & GAAGCTCAAGATACCATCC & CGACTTGTGCACAGATTCC \\
\hline Dps ferritine - II & TTGGTTAATTCAGCCGTTGT & ATTGATCACGATGTCCCAAC \\
\hline Polysaccharide biosynthesis export protein - III & CTCGTAAGCATGGTTCTCTC & ATTGGTTTGATGAAAAATGG \\
\hline Maltose phosphorylase - IV & ACGCATGATTCCTCATTATC & GGTCTTTCAAAATACCATCG \\
\hline Transcriptional regulator $-\mathrm{V}$ & TGGCAAACGTCTCAATCAAC & AGCTTACGGCTGATGCTTT \\
\hline Predicted transcriptional regulator - VI & CAATCAAGCCGGAATAGTT & TGACCAGTTCGAATGAATTC \\
\hline Alcohol-sugar dehydrogenase - VII & GGAAACAATTTACGCTTGC & CGGCCTGTTTGATAAAGAA \\
\hline Copper chaperone - VIII & ССТССТАСТTAАССТTGACG & AGTCCCACCTCCTGAATAAA \\
\hline Thioredoxin - IX & GTTTCTGAAGACCCGCTTA & TGATGCCCCCTTCGTAAT \\
\hline Glycerol uptake facilitator protein $-X$ & CTAACGCATTCCTGAAGAAC & CCCAACTATATTCCCAGTGA \\
\hline Glycosyltransferases involved in cell wall biogenesis - XI & TGTTAACGATACGAAGCGCG & GAATCACTCCATTCCGTCACC \\
\hline DpsA - XII & CGCCAGGTTCAAAATGTCTT & TCAATTCGTATTCCCGAAGC \\
\hline
\end{tabular}

PCR and its presence was revealed by an amplification signal on electrophoresis gel according to the conditions listed by Renouf et al. (2008).

\section{Physiological tests: Evaluation of the tolerance of strains against high levels of octanoic and decanoic acid}

Firstly, medium-chain fatty acid sensitivity was assayed by measuring the minimum inhibitory concentration (MIC) on Petri dishes containing medium composed of commercial red grape juice $(250 \mathrm{~mL} / \mathrm{L})$, yeast extract $(5 \mathrm{~g} / \mathrm{L})$, Tween $80(1 \mathrm{~mL} / \mathrm{L})$, and agar $(20 \mathrm{~g} / \mathrm{L}), \mathrm{pH}$ adjusted to 4.8 with $\mathrm{KOH}$ and containing different fatty acid concentrations. For octanoic acid, the range analysed was between $10 \mathrm{~g} / \mathrm{L}$ and $10 \mathrm{mg} / \mathrm{L}(10,5,2.5,1.25,0.6$, $0.4,0.25,0.2,0.15,0.1,0.05,0.025,0.01 \mathrm{~g} / \mathrm{L})$. For decanoic acid, for which the natural concentration in wine is generally four to five times lower, the range was between $2.5 \mathrm{~g} / \mathrm{L}$ and $5 \mathrm{mg} / \mathrm{L}(2.5$, $1.25,0.6,0.4,0.25,0.2,0.15,0.1,0.05,0.025,0.01,0.005 \mathrm{~g} / \mathrm{L})$. Then $10 \mu \mathrm{L}$ of a single culture of each strain were plated on these Petri dishes at an initial concentration of $10^{6}$ cell $/ \mathrm{mL}$, with the concentration being estimated by epifluorescence, according to the protocol developed by Millet and Lonvaud-Funel (2000), in the pre-culture liquid containing the same medium but without agar and fatty acids. The MICs were scored by the first concentration at which the absence of colonies on the agar surface was observed after ten days of incubation in an anaerobic environment at $25^{\circ} \mathrm{C}$. A positive control was prepared without any fatty acid addition to the agar. Trials were done in duplicate.

Secondly, the resistance to octanoic and decanoic acid was investigated under oenological conditions by evaluating the relationship between the population estimated by epifluorescence at $2 \mathrm{~h}$ and the population counted at $24 \mathrm{~h}$. Two wines were used: a white wine made from Chardonnay $(\mathrm{pH}=3.1$, ethanol content $=13.4 \%$ vol., total $\mathrm{SO}_{2}=55 \mathrm{mg} / \mathrm{L}$ ) and a red wine made from Merlot $\left(\mathrm{pH}=3.6\right.$, ethanol content $=14.5 \%$ vol., $\mathrm{SO}_{2}=42 \mathrm{mg} / \mathrm{L}$ and total phenolic index $=68$ ). After completion, the octanoic acid concentration equal to $60 \mathrm{mg} / \mathrm{L}$ and the decanoic acid concentration equal to $30 \mathrm{mg} / \mathrm{L}$ were adjusted using GC/FID (Bertrand et al., 1978). Each strain was inoculated at a concentration of $10^{6}$ cells/ $\mathrm{mL}$. Experiments were done in triplicate.

\section{Monitoring strain behaviour during winemaking}

Two post-AF wines were used. Theses wines were collected at the cellar after alcoholic fermentation and sterilised by filtration $(0.45 \mu \mathrm{m})$. The red, a Merlot wine from the Bordeaux region, was chosen for its high ethanol content (L-malic acid $=2.4$ $\mathrm{g} / \mathrm{L}, \mathrm{pH}=3.6$, ethanol content $=15.5 \%$ vol., $\mathrm{SO}_{2}=42 \mathrm{mg} / \mathrm{L}$ and total phenolic index $=68$ ). The white, a Chardonnay from Burgundy, was chosen for its low $\mathrm{pH}$ (L-malic acid $=3.1 \mathrm{~g} / \mathrm{L}, \mathrm{pH}$ $=3.0$, ethanol content $=12.8 \%$ vol., total $\mathrm{SO}_{2}=72 \mathrm{mg} / \mathrm{L}$ ) and its important levels of octanoic acid (38 mg/L) and decanoic acid (22 $\mathrm{mg} / \mathrm{L}$ ). For this wine, the combination of the low $\mathrm{pH}$ and the high total $\mathrm{SO}_{2}$, in addition to the medium-chain fatty acids, constituted a severely constraining medium for the lactic bacteria. Each strain was inoculated at $10^{6} \mathrm{cell} / \mathrm{mL}$ - at the end of AF for the white wines, and five days later for the red wines. Experiments were done in bottles of $1 \mathrm{~L}$ in triplicate. Fermentations were conducted at $20^{\circ} \mathrm{C}$. One day after the inoculation, organism control was estimated by the viable population observed in epifluorescence. MLF progress was monitored by dosing with L-malic acid by enzymatic determination (Boehringer Mannheim $\mathrm{GmbH}$ ).

\section{RESULTS}

Evidence of the $\mathrm{L}$ or $\mathrm{H}$ sequences and presence of the $\mathbf{1 2}$ genes

Concerning the research on the rpoB mutation, six strains had sequence L: Lactoenos SB3 $\AA$, Lactoenos 450 PreAc $\AA$, Lactoenos 350 PreAc ${ }^{\circledR}$, IOEB-SARCO 268, IOEB-SARCO 433 and IOEB 1491. The other had sequence $H$.

Besides 1491, which served as a positive control for the presence of the first 11 genes tested, the strain possessing the most important number of genes was IOEB-SARCO 433a, with 10 genes, followed by Lactoenos $350 \AA$ and Lactoenos SB3 $\AA$, with six genes each (Table 3). IOEB-SARCO 455 had no gene, 
and Lactoenos B16® only one. The cadmium-transporting P-type ATPase and the copper chaperone genes were not detected in the strains tested, except in IOEB 1491. Inversely, IOEB 1491 had all genes except the DpsA.

\section{Minimum inhibitory concentrations of octanoic and decanoic} acid

Table 4 lists the MICs of the ten strains tested. IOEB-SARCO 455 was very sensitive. Quite low resistance was displayed by Lactoenos B16, IOEB-SARCO 433a and IOEB-SARCO 384, while medium resistance was exhibited by Lactoenos SB3 ${ }^{\circ}$ and Lactoenos 450®. IOEB-SARCO 268, Lactoenos 350® and Malolactic starter A were the most resistant strains. In general, resistance to octanoic acid was better than to decanoic acid, except for Lactoenos $450 \operatorname{PreAc} \AA$, which displayed equal sensitivity. This infers that the inhibitory effect of decanoic acid is higher than that of octanoic acid.

\section{Survival rate in wines spiked with fatty acids}

In the wine, IOEB-SARCO 455 was the least resistant strain (Table 5). For the white wines, Lactoenos 350® presented the best score, and for the red it was Malolactic starter A, just ahead of IOEB 1491, which also displayed good tolerance but only in the red wine. In the red wine, Lactoenos $450 \AA$, Lactoenos SB3 ${ }^{\circledR}$ and IOEB-SARCO 384 showed slight growth between the two measures, but their populations dropped in the white wine by an order of magnitude $(0.1<\tau 24<1)$. IOEB-SARCO 268 showed good resistance in both wines.

\section{Monitoring of malolatic fermentations}

Three groups were established in the red wine according to the delay necessary to complete MLF (Fig. 1). The first group contained the strains that finished MLF on the twelfth day; minimal difference existed between these strains. Malolactic starter A and IOEB-SARCO 433a commenced fermentation

TABLE 3

Presence $(+)$ or absence $(-)$ of the genes tested in the strains.

\begin{tabular}{|c|c|c|c|c|c|c|c|c|c|c|c|c|c|}
\hline Genes & I & II & III & IV & $\mathbf{V}$ & VI & VII & VIII & IX & $\mathbf{X}$ & XI & XII & Total of genes \\
\hline 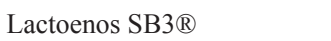 & - & - & + & - & - & + & - & + & - & + & + & + & $6 / 12$ \\
\hline Lactoenos $450 ®$ & - & - & + & - & - & - & - & - & - & - & - & + & $2 / 12$ \\
\hline Lactoenos $350 ®$ & - & - & + & - & - & + & - & + & - & + & + & + & $6 / 12$ \\
\hline Lactoenos B16® & - & - & - & - & - & - & - & - & - & - & - & + & $1 / 12$ \\
\hline Malolactic starter A & - & - & + & - & - & + & - & + & - & - & + & - & $4 / 12$ \\
\hline IOEB-SARCO 268 & - & - & + & - & - & + & - & + & - & + & + & - & $5 / 12$ \\
\hline IOEB-SARCO 384 & - & + & - & - & - & + & - & + & + & - & + & - & $5 / 12$ \\
\hline IOEB-SARCO 433a & - & + & + & + & + & + & - & + & + & + & + & + & $10 / 12$ \\
\hline IOEB-SARCO 455 & - & - & - & - & - & - & - & - & - & - & - & + & $1 / 12$ \\
\hline IOEB 1491 & + & + & + & + & + & + & + & + & + & + & + & - & $11 / 12$ \\
\hline On the totality of the strains & $1 / 10$ & $3 / 10$ & $6 / 10$ & $2 / 10$ & $2 / 10$ & $7 / 10$ & $1 / 10$ & $7 / 10$ & $3 / 10$ & $5 / 10$ & $7 / 10$ & $6 / 10$ & \\
\hline
\end{tabular}

TABLE 4

Comparison of minimum inhibitory concentrations on solid medium.

\begin{tabular}{lll}
\hline Strains & $\begin{array}{l}\text { Octanoic } \\
\text { acid }(\mathbf{m g} / \mathbf{L})\end{array}$ & $\begin{array}{l}\text { Decanoic } \\
\text { acid }(\mathbf{m g} / \mathbf{L})\end{array}$ \\
\hline Lactoenos SB3® & 250 & 100 \\
Lactoenos 350® & 400 & 250 \\
Lactoenos 450® & 250 & 250 \\
Lactoenos B16® & 100 & 50 \\
Malolactic starter A & 400 & 100 \\
IOEB-SARCO 268 & 400 & 100 \\
IOEB-SARCO 384 & 100 & 100 \\
IOEB-SARCO 433a & 200 & 100 \\
IOEB-SARCO 455 & 25 & 25 \\
IOEB 1491 & 250 & 50 \\
\hline
\end{tabular}

TABLE 5

Resistance in wine spiked with octanoic and decanoic acid by estimation of the ratio between epifluorescence and the population counted at two hours and 24 hours after inoculation.

\begin{tabular}{lll}
\hline Strains & White wine & Red wine \\
\hline Lactoenos SB3 ${ }^{-}$ & $0.22 \pm 0.02$ & $1.81 \pm 0.03$ \\
Lactoenos 350® & $4.1 \pm 0.4$ & $3.2 \pm 0.2$ \\
Lactoenos 450® & $0.14 \pm 0.01$ & $1.8 \pm 0.2$ \\
Lactoenos B16® & $0.12 \pm 0.04$ & $0.10 \pm 0.02$ \\
Malolactic starter A & $1.6 \pm 0.1$ & $4.8 \pm 0.5$ \\
IOEB-SARCO 268 & $2.26 \pm 0.01$ & $1.44 \pm 0.02$ \\
IOEB-SARCO 384 & $0.12 \pm 0.04$ & $1.3 \pm 0.2$ \\
IOEB-SARCO 433a & $0.2 \pm 0.2$ & $0.2 \pm 0.1$ \\
IOEB-SARCO 455 & $0.0004 \pm 0.0002$ & $0.006 \pm 0.002$ \\
IOEB 1491 & $0.64 \pm 0.08$ & $4.0 \pm 0.4$ \\
\hline
\end{tabular}


TABLE 6

Results of the epifluorescence observation in the wines one day after inoculation. ND: not detected; the threshold of the method is equal to $10^{3}$ cell $/ \mathrm{mL}$.

\begin{tabular}{lll}
\hline Name of the strain & Red wine & White wine \\
\hline Lactoenos SB3 & $4.9 \pm 0.1 \times 10^{6} \mathrm{cell} / \mathrm{mL}$ & $6.9 \pm 0.1 \times 10^{5} \mathrm{cell} / \mathrm{mL}$ \\
Lactoenos 350® & $1.5 \pm 0.5 \times 10^{7} \mathrm{cell} / \mathrm{mL}$ & $9.0 \pm 0.5 \times 10^{6} \mathrm{cell} / \mathrm{mL}$ \\
Lactoenos 450® & $2.1 \pm 0.7 \times 10^{6} \mathrm{cell} / \mathrm{mL}$ & $2.0 \pm 0.2 \times 10^{6} \mathrm{cell} / \mathrm{mL}$ \\
Lactoenos B16® & $5.5 \pm 0.5 \times 10^{5} \mathrm{cell} / \mathrm{mL}$ & $\mathrm{ND}$ \\
Malolactic starter A & $4.3 \pm 0.1 \times 10^{6} \mathrm{cell} / \mathrm{mL}$ & $6.9 \pm 0.1 \times 10^{6} \mathrm{cell} / \mathrm{mL}$ \\
IOEB-SARCO 268 & $4.4 \pm 0.1 \times 10^{6} \mathrm{cell} / \mathrm{mL}$ & $2.4 \pm 0.1 \times 10^{6} \mathrm{cell} / \mathrm{mL}$ \\
IOEB-SARCO 384 & $2.0 \pm 0.4 \times 10^{6} \mathrm{cell} / \mathrm{mL}$ & $4.4 \pm 0.4 \times 10^{5} \mathrm{cell} / \mathrm{mL}$ \\
IOEB-SARCO 433a & $8.1 \pm 0.9 \times 10^{5} \mathrm{cell} / \mathrm{mL}$ & $\mathrm{ND}$ \\
IOEB-SARCO 455 & $\mathrm{ND}$ & $\mathrm{ND}$ \\
IOEB 1491 & $4.9 \pm 0.7 \times 10^{5} \mathrm{cell} / \mathrm{mL}$ & $7.0 \pm 0.7 \times 10^{5} \mathrm{cell} / \mathrm{mL}$ \\
\hline
\end{tabular}

rapidly, whereas Lactoenos $450 \AA$ and Lactoenos $350 \AA$ had a latency phase, although they exhibited higher malolactic activity which compensated for the delay in initiation. The second group included strains for which 12 to 25 days were necessary to complete MLF. This group contained Lactoenos SB3 ${ }^{2}$, Lactoenos B16® and IOEB-SARCO 384. As mentioned previously, differences existed regarding the latency period between inoculation and L-malic acid consumption. From the beginning of monitoring, strain IOEB-SARCO 384 showed significant activity, while a week was required for the others before the start of fermentation. Later, high malolactic activity allowed them to catch up. The last group included the strains that failed. IOEB-SARCO 268 started L-malic acid degradation, but stopped when the concentration was close to $1.0 \mathrm{~g} / \mathrm{L}$, despite a short initial latency phase before the beginning of MLF. IOEB-SARCO 455 degraded no L-malic acid.

Two groups were established in the white wine. The first group contained the strains that completed MLF, while the second included the strains that failed. This group included more strains than that of the red wine, since IOEB-SARCO 384, IOEB-SARCO 433a, IOEB-SARCO 455, IOEB 1491 and Lactoenos B16 ${ }^{\circledR}$ failed without any commencement of L-malic acid degradation. Amongst the strains that completed MLF, Lacteonos 350®, Lactoenos 450 PreAc $\AA$, IOEB-SARCO 268 and Malolactic starter A presented the best kinetic profiles, without differences in terms of fermentation duration. Twenty-two days were required by Lactoenos 350 PreAc ${ }^{\circledR}$, IOEB-SARCO 268 and Malolactic starter A, 26 days by Lactoenos 450 PreAc $($, and 55 days by Lactoenos SB3®.

Table 6 contains the results obtained by epifluorescence analysis done for the two trials one day after each inoculation. These data showed that the differences in terms of latency period in the red wine were not always the consequence of the difference in the initial populations: IOEB-SARCO 433a had one of the lowest initial populations but was the first to begin the L-malic acid degradation, and Lactoenos $350 \operatorname{PreAc} \AA$, which had the highest initial population, started MLF four days after inoculation. In the white wine, the failure of some strains (Lactoenos B16®, IOEB-
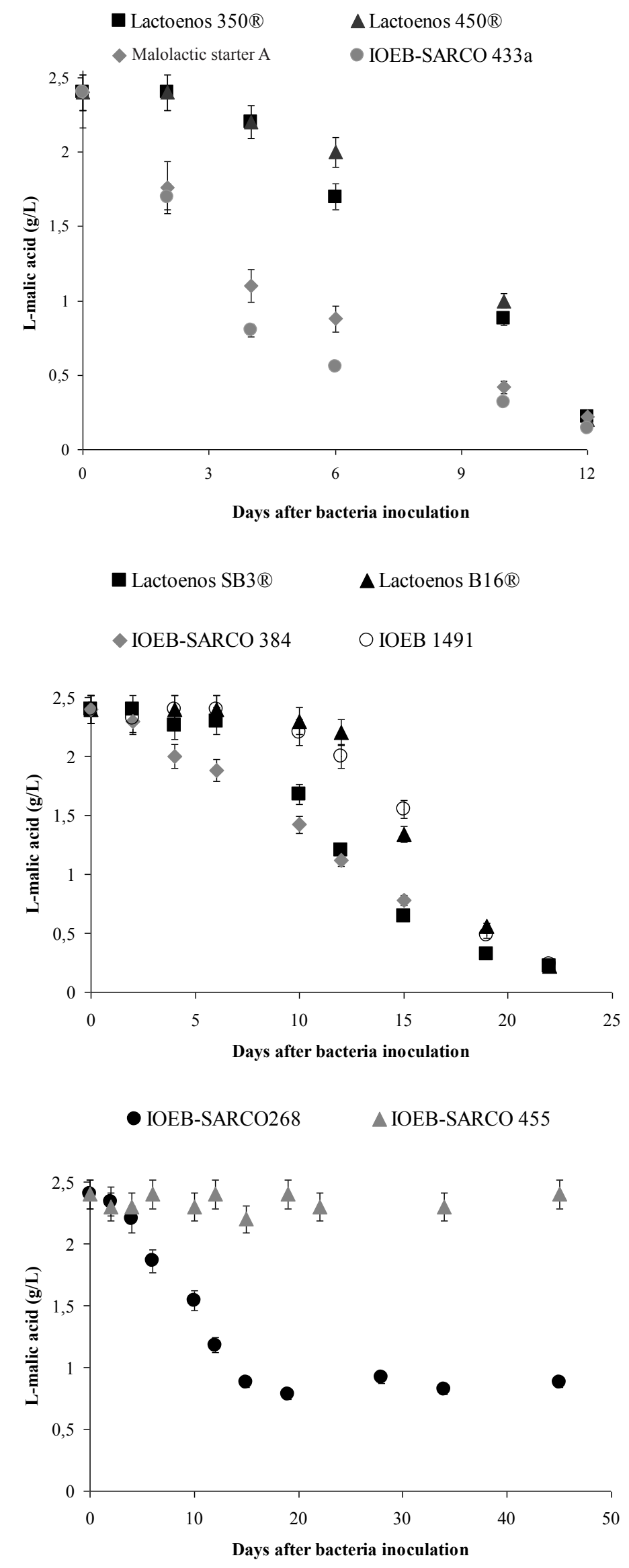

FIGURE 1

Kinetic profiles of the progression of MLF in the red wine. 
SARCO 433a and IOEB-SARCO 455) could be explained by an inoculation failure, since no viable bacteria were detected by epifluorescence one day after inoculation. For the others (IOEBSARCO 384 and IOEB 1491), viable bacteria were observed after inoculation, but they were unable to become active.

\section{DISCUSSION}

It is interesting to note that, in relation to strains that are already marketed and that have proven their strong oenological abilities through use by winemakers globally, it is difficult to link these qualities through genetic data gained from this work with reference to fundamental studies on the genetics of $O$. oeni. For The commercial strains did not have a large number of the genes tested, but merely an average number. Lactoenos B16 ${ }^{\circledR}$, one of the first commercial strains isolated from Champagne wine that is widely used by winemakers, notably in sparkling-based wines that often are constraining for the bacteria (low $\mathrm{pH}$, high levels of $\mathrm{SO}_{2}$ ), has only one gene, DpsA. In contrast, Malolactic starter A, a very effective commercial strain, has some genes but not DpsA. From a physiological point of view, it is important to note that the commercial strains showed good tolerance to medium-chain fatty acids, notably Lactoenos 350 PreAc $\AA$. Probably, since this feature was not previously analysed during strain selection, tolerance to medium-chain fatty acids was indirectly taken into account during the numerous winemaking trials conducted to prove the quality of the strains before genetics tests were developed. This suggests that, even if genetic data provide better characterisation of the strains for some physiological and oenological traits, winemaking trials remain indispensable to confirm the oenological suitability of the strains. Regarding the tests performed here, it interesting to note that sensitivity to medium-chain fatty acids was higher in white wine, probably because the $\mathrm{pH}$ plays a cumulative role with these compounds.

The MLF tests performed in red wine with a high ethanol content and white wine with a low $\mathrm{pH}$ parallel some of the results obtained from genetic and physiological testing. IOEB SARCO455 , which is a poor strain in terms of the number of genes (with only the gene DpsA), had the lowest tolerance to fatty acids and failed in both winemaking tests, while some commercial strains (Lactoenos 350 PreAc $\AA$, Lactoenos 450 PreAc $\AA$ and Malolactic starter A) that had higher numbers of genes and tolerance to medium-chain fatty acids were among the most efficient.

Regarding potential new strains, it is interesting to note that IOEB-SARCO433a seems be an efficient strain in red wine that is high in alcohol. This strain has a significant number of genes. In the red wine, despite a sub-optimal survival rate after inoculation, it was the first strain to begin L-malic acid degradation. In the white wine, inoculation failed with IOEB-SARCO 433a, probably because its resistance to medium-chain fatty acids is poor, or because it is not an efficient strain at a low $\mathrm{pH}$, or due to a combination of these two parameters. In the white wine, IOEBSARCO 268 exhibited interesting responses. This strain does not possess many genes, but it has high tolerance to medium-chain fatty acids. For the trial done in the red wine, the survival rate of IOEB-SARCO 268 was good, but it could not complete MLF, perhaps because its ethanol tolerance is poor. IOEB-SARCO 268 has half as many genes as the IOEB-SARCO 433a strain.

These data suggest that IOEB-SARCO 433a could be a good candidate strain to achieve rapid FML in red wines in which alcohol appears to be increasingly problematic each year (Zapparoli et al., 2009), and IOEB-SARCO 268 could be effective in difficult white wines in which fatty acids are too restrictive for other bacteria. Many more tests have to be done with various wines to confirm these hypotheses, especially the absence of some undesirable phenomena such as production of biogenic amines (Nannelli et al., 2008).

Another important aspect shown in this study is the latency period between the inoculation of the bacteria and the beginning of L-malic acid degradation, and the difficulty of linking this delay to the survival rate measured just after inoculation.

\section{CONCLUSION}

It is important to note that advancements in the understanding of genetics provide other tools to characterise $O$. oeni strains beyond the simple physiological tests previously used. However, since all important physiological and oenological aspects cannot be characterised by genetic data alone, physiological and oenological testing will always be necessary to ensure strain effectiveness. In terms of more exhaustive genetic tests, sequencing (Zé-Zé et al., 2000) should be instructive. Our study underlines the importance of the full characterisation of two physiological traits: resistance to medium-chain fatty acids and wine $\mathrm{pH}$. Furthermore, the reason for the short latency period exhibited by certain strains should be investigated.

To provide efficient bacteria for MLF in difficult wines, it seems necessary to differentiate the wine characteristics that constitute the exact nature of the difficulty. Indeed, it seems illusory to conduct MLF in a red wine with a high ethanol content and in a white wine with a low $\mathrm{pH}$ with the same strain. Studying specific strains for each of type of bacterial inhibition would appear to provide the greatest chance of success.

\section{LITERATURE CITED}

Athané, A., Bilhère, E., Bon, E., Morel, G., Lucas, P., Lonvaud-Funel, A. \& Le Marrec, C., 2008. Characterization of an acquired-dps-containing gene island in the lactic acid bacterium Oenococcus oeni. J. Appl. Microbiol. 105, 1866-1875.

Bertrand, A., Marly-Brugerolle, C. \& Sarre, C., 1978. Influence du débourbage des moûts et du sulfitage sur les teneurs en substances volatiles des vins et eauxde-vie. Conn. Vigne Vin 12, 35-48.

Bilhère, E., Lucas, P.M., Claisse, O. \& Lonvaud-Funel, A., 2009. Multilocus sequence typing of Oenococcus oeni: detection of two subpopulations shaped by intergenic recombination. Appl. Environ. Microbiol. 75, 1291-1300.

Bon, E., Delaherche, A., Bilhère, E., De Daruvar, A., Lonvaud-Funel, A. \& Le Marrec, C., 2009. Oenococcus oeni genome plasticity is associated with fitness. Appl. Environ. Microbiol. 75, 2079-2090.

Choi, S.H., Baumler, D.J. \& Kaspar, C.W., 2000. Contribution of dps to acid stress tolerance and oxidative stress tolerance in Escherichia coli O157:H7. Appl. Environ. Microbiol. 66, 3911-3916.

Delaherche, A., Bon, E., Dupre, A., Lucas, M., Arveiller, B., De Daruvar, A. \& Lonvaud-Funel, A., 2007. Intraspecific diversity of Oenococcus oeni strains determined by sequence analysis of target genes. Appl. Microbiol. Biotechnol. 73, 394-403.

De las Rivas, B., Marcobal, A. \& Munoz, R., 2004. Allelic diversity and population structure in Oenococcus oeni as determined from sequence analysis of housekeeping genes. Appl. Environ. Microbiol. 70, 7210-7219.

Drici-Cachon, Z., Guzzo, J., Cavin, J.F. \& Divies, C., 1996. Acid tolerance in Leuconostoc oenos. Isolation and characterization of an acid resistant mutant. Appl. Microbiol. Biotechnol. 44, 785-789. 
Guzzo, J., Coucheney, F., Pierre, F., Fortier, L., Delmas, F., Divies, C. \& TourdotMaréchal, R., 2002. Acidophilic behaviour of the malolactic bacterium Oenococcus oeni. Sciences des Aliments 22, 107-111.

Lonvaud-Funel, A., Joyeux, A. \& Desens, C. 1988. Inhibition of malolactic fermentation of wines by products of yeast metabolism. J. Sci. Food Agric. 44, 183-191.

Marcobal, A.M., Sela, D.A., Wolf, Y.I., Markarova, K.S. \& Mills, D.A., 2008. Role of the hypermutability in the evolution of the genus Oenococcus. J. Bacteriol. 190, 564-570.

Millet, V. \& Lonvaud-Funel, A., 2000. The viable but non-culturable state of microorganism during storage. Lett. Appl. Microbiol. 30, 136-141.

Nannelli, F., Claisse, O., Gindreau, E., De Revel, G., Lonvaud-Funel, A. \& Lucas, P.M., 2008. Determination of lactic acid bacteria producing biogenic amines in wine by the quantitative PCR methods. Lett. Appl. Microbiol. 47, 594-599.
Renouf, V., Delaherche, A., Claisse, O. \& Lonvaud-Funel, A., 2008. Correlation between indigenous Oenococcus oeni strain resistance and the presence of significant genetic markers. J. Ind. Microbiol. Biotechnol. 35, 27-33.

Renouf, V., Cadet-Vayssieres, L., Claisse, O. \& Lonvaud-Funel, A., 2009. Genetic and phenotypic evidence for two groups of Oenococcus oeni strains and their prevalence during winemaking. Appl. Biotech. Microbiol. 10.1007/s00253-0081843-1.

Romano, A., Perello, M.C., De Revel, G. \& Lonvaud-Funel, A., 2008. Growth and volatile compound production by Brettanomyces/Dekkera bruxellensis in red wine. J. Appl. Microbiol. 104, 1577-1585.

Zapparoli, G., Tosi, E., Azzolini, M., Vagnoli, P. \& Kriger, S., 2009. Bacterial inoculation strategies for the achievement of malolactic fermentation in highalcohol wines. S. Afr. J. Enol. Vitic. 30, 49-55.

Zé-Zé, L., Tenreiro, R. \& Paveia, H., 2000. The Oenococcus oeni genome: physical and genetic mapping of strain GM and comparison with the genome of a 'divergent' strain PSU1. Microbiol. 146, 3195-3204. 